\title{
Abstract: Catalytic reaction between adsorbed oxygen and hydrogen on $R h(111)^{a)}$
}

\author{
J. T. Yates, Jr, ${ }^{\text {b) Patricia A. Thiel, }{ }^{(c)} \text { and W. H. Weinberg }}{ }^{d)}$ \\ Division of Chemistry and Chemical Engineering, California Institute of Technology, Pasadena, California 91125 \\ (Received 21 September 1978; accepted 6 November 1978)
}

PACS numbers: $68.20 .+t, 82.65 . J v, 68.45 . \mathrm{Da}, 79.20 . \mathrm{Fv}$

We have studied both the kinetics of adsorption of $\mathrm{O}_{2}$ by $\mathrm{Rh}(111)$ and the subsequent reaction of chemisorbed oxygen with $\mathrm{H}_{2}(g)$ using Auger spectroscopy, low-energy electron diffraction (LEED), and thermal desorption mass spectrometry.

At $335 \mathrm{~K}, \mathrm{O}_{2}$ chemisorbs on $\mathrm{Rh}(111)$ into a mixture of ordered and disordered species. ${ }^{1}$ By means of careful studies of the oxygen Auger intensity as a function of exposure to $\mathrm{O}_{2}(\mathrm{~g})$, it was found that the adsorption kinetics obey a Langmuir rate law involving a $\left(1-\theta_{0}\right)$ factor, rather than exhibiting the expected $\left(1-\theta_{0}\right)^{2}$ dependence for dissociative chemisorption (Fig. 1). This suggests that the chemisorption of $\mathrm{O}_{2}$ by $\mathrm{Rh}(111)$ proceeds via a step involving a single $\mathrm{Rh}$ site and an $\mathrm{O}_{2}$ molecule; subsequent dissociation is not rate controlling. There are numerous examples of the bonding of $\mathrm{O}_{2}$ to transition metal atoms in the inorganic chemical literature. ${ }^{2,3}$ Both peroxo complexes involving $\pi$-bonded $\mathrm{O}_{2}$ and superoxo complexes bound end-on to metal atoms have been produced and studied spectroscopically. We suggest that a species of this kind may be a transient species in the chemisorption and dissociation of $\mathrm{O}_{2}$ by $\mathrm{Rh}(111)$.

The adsorption of $\mathrm{O}_{2}$ was studied also by LEED using a Faraday cup collector for measurement of beam intensity as a function of $\mathrm{O}_{2}$ exposure. A " $(2 \times 2)$ " LEED pattern forms upon $\mathrm{O}_{2}$ adsorption. Below $\theta_{0}=0.45$, the intensity of one of the overlayer beams $I_{(1, \overline{1 / 2})}$ was accurately proportional to $\theta_{0}^{2}$ as expected for island formation with net pairwise attractive forces operating. ${ }^{4}$ Beyond this point in covverage, more complex behavior is observed, with $I_{(1, \overline{1} / 2)}$ increasing more rapidly than $\theta_{0}^{2}$ to a sharp maximum at $\theta_{0}=0.65$. This is designated the initial ordering region in Fig. 2. At still higher $\theta_{0}$, a substantial decrease in $I_{(1, \overline{1} / 2)}$ occurs, followed by a twentyfold

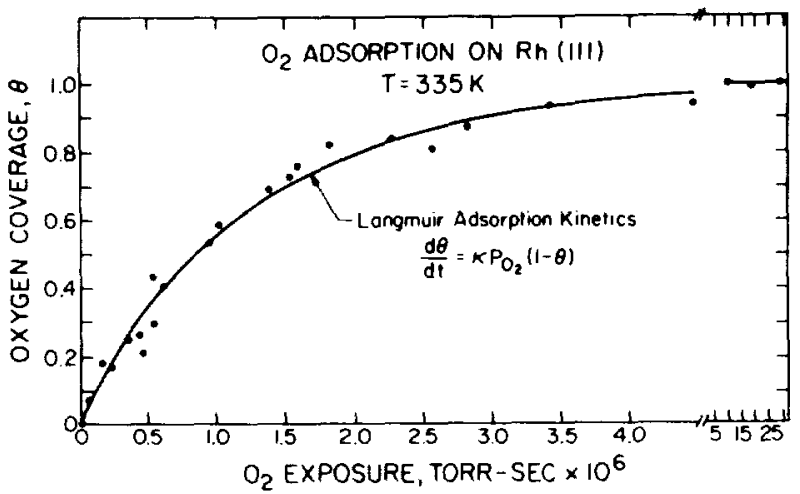

FIc. 1. Kinetics of $\mathrm{O}_{2}$ adsorption on $\mathrm{Rh}(111)$ at $335 \mathrm{~K}$. The fit to $\left(1-\theta_{0}\right)$ kinetics has been found to be superior to a $\left(1-\theta_{0}\right)^{2} \mathrm{fit}$. increase in $I_{(1, \overline{1} / 2)}$ above $\theta_{0} \simeq 0.9$. This is designated the final ordering region in Fig. 2. We propose the following general picture to explain the intensity-exposure behavior for $\mathrm{O}_{2}$ chemisorption on $\mathrm{Rh}(111)$ at $335 \mathrm{~K}$ :

stage $1: \theta_{0} \lesssim 0.45$, island growth with net pairwise attractive interactions:

stage 2: $0.45 \leqslant \theta_{0} \leqslant 0.65$, three- or more-body attractive interactions giving accelerated ordering.

stage 3: $0.65 \leqslant \theta_{0} \lesssim 0.90$, net many-body repulsive interactions giving loss of order;

stage 4: $\theta_{0} \gtrsim 0.90$, final filling in of empty sites with optimally ordered overlayer.

It is interesting to note that on $\mathrm{Ru}(001)$, which is also a hexagonally symmetric surface, Madey et al. ${ }^{5}$ observed very similar intensity-exposure behavior for an oxygen overlayer beam in the " $(2 \times 2)$ " pattern.

It was found that in the final ordering region, the rate of change of $I_{\left(1, \frac{1}{1 / 2}\right)}$ was accurately proportional to the rate of change of oxygen coverage; hence, the LEED intensity may be used for studying the kinetics of surface reactions involving the ordered oxygen in this region.

In Fig. 3, a plot is shown of the initial rate of ordered oxygen depletion, using $\left[d I_{(1, \sqrt[1]{1 / 2})} / d t\right]$, as a function of the steady state $P_{\mathrm{H}_{2}}$. The depletion process is first order in $\boldsymbol{P}_{\mathrm{H}_{2}}$. Consideration of the elementary surface reactions involved in the formation of $\mathrm{H}_{2} \mathrm{O}(\mathrm{g})$ suggests that the first step for $\mathrm{H}_{2}$ interaction with ordered oxygen is

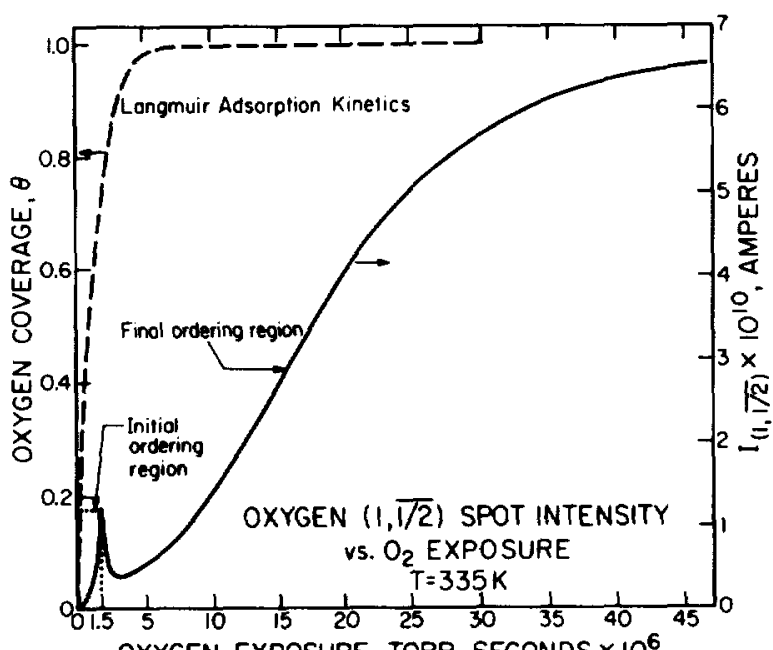

FIG. 2. Oxygen $(1, \overline{1 / 2})$ LEED beam intensity as a function of $O_{2}$ exposure at $335 \mathrm{~K}$. The final ordering region occurs above $\theta_{0}=0.90$ 


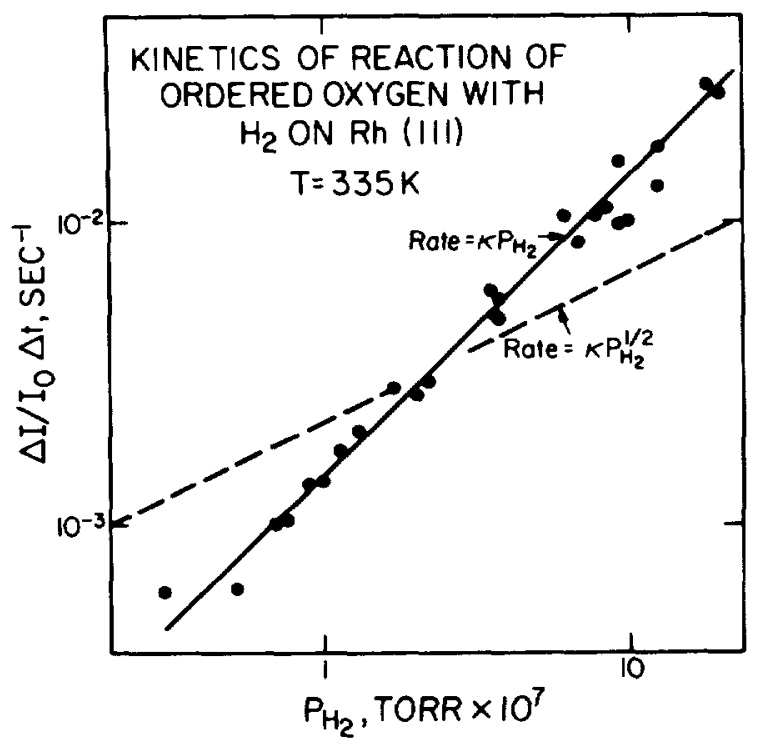

Fic. 3. Kinetics of reaction of ordered oxygen with $\mathrm{H}_{2}(\mathrm{~g})$ on $\mathrm{Rh}(111)$ at 335 $\mathrm{K}$. The rate of reaction was measured by observing $\left[d I_{(1, \overline{1} / 2)} / d t\right]$ at various $P_{\mathbf{H}_{2}}$.

$$
\text { Ordered } \mathrm{O}+\mathrm{H}_{2}(g) \underset{k_{2}}{\stackrel{k_{1}}{\rightleftarrows}} 2 \mathrm{H}(\mathrm{ads})+\text { Ordered } \mathrm{O}
$$

with $\mathrm{k}_{2}=0$. Ordered $\mathrm{O}$ provides trap sites for $\mathrm{H}(\mathrm{ads})$, preventing the $k_{2}$ process and giving first-order kinetics in $P_{H_{2}}$. By studying the rate of reaction in the temperature region, $313 \mathrm{~K} \leq T \leq 457 \mathrm{~K}$, the activation energy was measured to be $5.3 \pm 0.3 \mathrm{kcal} / \mathrm{mol}^{-1}$. For each reaction event, order is lost from a domain of which the area is approximately 300 $\AA^{2}$.
Auger spectroscopy was used also to monitor surface oxygen coverage during reaction with $\mathrm{H}_{2}(g)$. The rates measured in this fashion in a particular range of $\boldsymbol{P}_{\mathbf{H}_{2}}$ are thought to be determined mainly by the reaction of disordered oxygen with $\mathrm{H}_{2}(g)$. Here, the kinetics are found to be one-half order in $P_{\mathrm{H}_{2}}$, consistent with a first step:

$$
\text { Disordered } \mathrm{O}+\mathrm{H}_{2}(g) \underset{k_{2}}{\stackrel{k_{1}}{\rightleftarrows}} 2 \mathrm{H}(\text { ads })+\text { Disordered O }
$$

where $k_{2}>0$.

This system provides an excellent example of the influence of geometrical factors in determining the kinetics of a heterogeneously catalyzed surface reaction.

Acknowledgment: This research was supported by the Army Research Office under Grant No. DAHC04-750170

a) Research supported by the Army Research Office under Grant No DAHC04-75-0170. Complete paper to appear in Surface Science.

b) Sherman Fairchild Distinguished Scholar. Permanent Address: National Bureau of Standards, Washington, D.C. 20234.

c) National Science Foundation Predoctoral Fellow.

d) Alfred P. Sloan Foundation Fellow, and Camille and Henry Dreyfus Foundation Teacher-Scholar

'P. A. Thiel, J. T. Yates, Jr. and W. H. Weinberg, J. Vac. Sci. Technol. 16, 438 (1979).

${ }^{2}$ L. Vaska, Accts. Chem. Res. 9, 175 (1976)

${ }^{3}$ G. A. Ozin and A. Vander Voet, Accts. Chem. Res. 6, 313 (1973).

${ }^{4} \mathrm{G}$. Ertl and J. Küppers, Low-Energy Electrons and Surface Chemistry (Verlag Chemie, Weinheim, 1974), pp. 216-220.

${ }^{5}$ T. E. Madey, H. A. Engelhardt, and D. Menzel, Surf. Sci. 48, 304 (1975) 